\title{
PENGENDALIAN KUALITAS PRODUK KANTONG SEMEN DENGAN MENGGUNAKAN SEVEN QUALITY CONTROL TOOLS (STUDI KASUS DI PT XYZ)
}

\author{
Vembri Noor Helia dan Ayu Wulandari Suyoto \\ Jurusan Teknik Industri, Fakultas Teknologi Industri, Universitas Islam Indonesia \\ e-mail: vembri@uii.ac.id
}

\begin{abstract}
ABSTRAK
Tujuan dari penelitian ini adalah untuk mengetahui pengendalian kualitas produksi kantong semen dengan menggunakan tujuh alat pengendalian kualitas (seven quality control tools) di PT XYZ plant Cirebon. Hal ini dilakukan karena terdapat reject melebihi target yang ditetapkan. Fungsi seven tools pada pengendalian kualitas adalah untuk mngetahui jenis cacat dan cacat yang dominan pada produk kantong semen PT XYZ plant Cirebon. Selain itu, dapat diketahui pula faktor-faktor penyebab terjadinya produk cacat yang dominan pada proses produksi kantong semen. Seven tools pada pengendalian kualitas meliputi check sheet, histogram, diagram tebar (scatter diagram), diagram pareto, peta kendali p, dan diagram fishbone. Jenis cacat yang dominan dari hasil penelitian ini adalah bottom gagal dengan jumlah persentase 60\%. Faktor-faktor penyebab dari cacat bottom gagal adalah dari sisi manusia, sisi material, sisi lingkungan, sisi metode, serta faktor penyebab utama adalah dari alat atau mesin, yaitu kurangnya perawatan, mesin tua, dan kurang presisi. Saran untuk perbaikan adalah melakukan maintenance secara rutin, melakukan pengecekan dan pembersihan tempat lem pada mesin, melakukan pemeliharaan lingkungan kerja dan melakukan training kepada pegawai produksi.
\end{abstract}

Kata kunci: produk cacat, pengendalian kualitas, seven tools, diagram fishbone

\begin{abstract}
The purpose of this study is to determine the quality control of the production of cement bags by using seven tools of quality control (seven quality control tools) in the XYZ plant Cirebon. The research is necessary because of the reject rate is exceeding the target from the company. The advantages by using seven tools on quality control for the company are understanding the types of defects and investigating the dominant defect. Moreover, the main factors that cause dominant defective products in the production process of cement bags will be concluded. Seven tools on quality control includes check sheets, histograms, stocking diagram (scatter diagram), Pareto diagrams, $p$ control chart, and fishbone diagrams. The dominant defect type of this research is the failed bottom with the percentage of $60 \%$. The causative factors of the defect failed bottom are from the human side, the material side, the environmental side, the methods, and the main factor is from the tool or machine. This is because of a lack of maintenance, old machinery, and lack of precision. The recommendations suggested for improvements are performing routine maintenance, checking and cleaning the glue container on the machine, performing maintenance for work environment and conduct training for production employees.
\end{abstract}

Keywords: reject, quality control, seven tools, fishbone diagram

\section{PENDAHULUAN}

Kebutuhan akan semen di Indonesia makin meningkat dari tahun ke tahun. Asosiasi Semen Indonesia menyebut permintaan semen di Indonesia meningkat 3 juta ton pada 2016 dari 62 juta ton pada 2015 disebabkan oleh peningkatan kebutuhan semen untuk percepatan pembangunan insfrasuktur, khususnya pada era pemerintahan Presiden Joko Widodo [1]. Semen digunakan untuk kebutuhan perumahan/umum dan infrastruktur dengan perbandingan kebutuhan antara keduanya adalah 30\% banding $70 \%$.
Semen terdiri dari semen curah (bulk cement) dan semen bag (bag cement). Penggunaan semen bag lebih tinggi dibandingkan dengan semen curah karena konsumen lebih terbiasa dengan penggunaan semen bag ini. Selain itu, penggunaan semen bag lebih fleksibel dari sisi jumlahnya jika dibandingkan dengan semen curah. Peningkatan penggunaan atau konsumsi terhadap semen curah mengalami peningkatan dari tahun ke tahun lebih tinggi maka terlihat bahwa masyarakat mulai terbiasa juga dengan penggunaan semen curah, khususnya untuk 
penggunaan semen dalam skala besar seperti untuk bangunan tinggi ataupun jembatan dan sebagainya.

PT XYZ bukan satu-satunya produsen semen di Indonesia. Terdapat beberapa perusahaan semen yang dapat dikategorikan sebagai kompetitor PT XYZ, antara lain PT Holcim dan PT Semen Gresik. Untuk dapat tetap menjadi pilihan pertama masyarakat, maka PT XYZ memiliki strategi-strategi yang diterapkan. Salah satu strategi yang dilakukan adalah tetap menjaga kualitas hasil produksi. Kantong semen merupakan bagian dari produksi semen yang juga harus mendapat perhatian.

Dalam paper penelitian kali ini akan dikaji pada pabrik yang berlokasi di Cirebon. Untuk menopang pengoperasian dan produksi semen, PT XYZ plant Cirebon didukung oleh sekian banyak divisi penunjang, dimana salah satu diantaranya adalah divisi pabrik kantong (Paper Bag Factory Section - disingkat PBF). Paper Bag Factory memiliki fasilitas untuk memproduksi dan memasok kebutuhan kantong untuk pengemasan semen, kantong yang diproduksi merupakan jenis Pasted bag.

Paper Bag Factory Section harus mempertahankan kualitas dan kuantitas kantung semen untuk dapat dilakukan proses pengemasan pada bagian Packing. Pada studi pendahuluan telah dilakukan terlebih dahulu observasi dan ditemukan permasalahan, yaitu ditemukannya sejumlah reject kantong semen pasted bag dengan jumlah tertentu dan belum terkontrol dengan baik. Pada tahun 2015 terdapat jumlah produksi sebanyak 55.563.992 kantong semen dengan jumlah reject adalah 93.341 kantong semen. Dari data tersebut maka didapatkan rata-rata persentase produk reject adalah $0,17 \%$.

Pada awalnya perusahaan tidak terlalu mempermasalahkan hal ini. Akan tetapi, jika hal ini dibiarkan terus menerus, maka akan dapat mengganggu kelancaran aliran proses produksi semen juga. Pengurangan produk cacat dapat dilakukan dengan pengendalian kualitas produksi baik dari segi proses maupun teknis. Menurut target dari perusahaan bahwa presentase cacat kantong semen yang dimiliki adalah tidak lebih dari $0,1 \%$, sehingga jika dibandingkan dengan nilai 0,17\% itu sudah melampaui batas atau target. Oleh karena itu, perlu diketahui apa yang menjadi penyebab cacat produk kantong semen dan bagaimana cara-cara untuk menanggulanginya. Tujuan dari penelitian ini adalah untuk mengetahui pengendalian kualitas dengan menggunakan tujuh alat pengendalian kualitas (seven quality control tools), jenis cacat dan cacat yang dominan pada produk kantong semen, mengetahui faktor-faktor penyebab terjadinya produk cacat yang dominan, serta saran-saran perbaikannya.

\section{Penelitian Terdahulu}

\section{KAJIAN PUSTAKA}

Terdapat beberapa metode pengendalian kualitas yang dapat digunakan dalam menyelesaikan permasalahan tersebut. Pengendalian dengan pendekatan Six Sigma dilakukan pada proses pengantongan semen di PT Semen Indonesia (Persero) Tbk [2]. Semula perusahaan hanya menggunakan diagram pareto saja, sehingga informasi yang diperoleh hanya dapat mengidentifikasi jenis cacat yang paling sering terjadi. Keuntungan dari pengendalian kualitas ini dapat diketahui penyebab terjadinya produk cacat.

Penggunaan metode yang lain dalam pengendalian kualitas juga dilakukan, yaitu dengan menggunakan pendekatan Kaizen dan analisis masalah dengan seven tools [3]. Penelitian ini mampu menunjukkan bagaimana Pengendalian Mutu Terpadu (Total Quality Control) sebagai pendekatan manajemen modern, dalam menjalankan suatu usaha untuk memaksimumkan daya saing perusahaan melalui perbaikan secara terus-menerus (continous improvement) atas produk atau bahan baku. Dengan penggunaan metode pengendalian kualitas ini dapat diketahui adanya penurunan cacat terbesar yakni pada benang, yaitu meleset, loncat, dan kendor. New seven tools juga dapat digunakan untuk pengendalian kualitas produk. Penelitian yang dilakukan di PT “C2B" ini ditujukan untuk mengetahui bagaimana pengendalian kualitas dilakukan oleh perusahaan khusus untuk produk "X24" [4]. 
Metode atau alat pengendalian kualitas sederhana yang dapat digunakan untuk menyelesaikan permasalahan adalah seven tools of quality control yaitu tujuh alat pengendalian kualitas. Dengan penggunaan tujuh alat ini dapat mengetahui persentase kecacatan produk, pengendalian data kecacatan, jenis cacat terbesar dan mengetahui penyebab kecacatan tersebut, sehingga dapat diberikan saran-saran untuk dapat mengatasi cacat terutama cacat yang paling dominan. Penggunaan seven tools telah dilakukan pada berbagai penelitian $[5,6]$.

\section{Pengendalian Kualitas}

Kualitas adalah kesesuaian untuk digunakan (fitness for use) [7]. Sedangkan "zero defect" yang berarti kesesuaian seratus persen dengan spesifikasi produk [8]. Pengendalian kualitas adalah suatu sistem yang terdiri dari pengujian, analisis dan tindakantindakan yang harus diambil dengan menggunakan kombinasi seluruh peralatan dan teknik-teknik yang berguna untuk mengendalikan kualitas suatu produk dengan ongkos minimal, sesuai dengan keinginan konsumen. Pengendalian kualitas merupakan satu dari tiga dasar proses pengendalian, yaitu perencanaan kualitas dan perbaikan kualitas yang merupakan trilogi [7].

Salah satu metode pengendalian dapat dilakukan secara statistik (Statistical Process Control atau SPC). SPC adalah satu dari pengembangan teknologi terbesar pada abad 21 karena memiliki prinsip mudah digunakan, memiliki dampak yang signifikan, dan dapat diaplikasikan dalam berbagai proses [9]. Terdapat tujuh alat utama yang disebut juga dengan seven quality control tools (7QC Tools) terdiri dari: 1) Histogram, 2) Check sheet, 3) Pareto chart, 4) Cause and effect diagram, 5) Defect concentration diagram, 6) Scatter diagram, 7) Control chart. Terdapat penelitian yang menyatakan bahwa sangat penting untuk menerapkan semua 7QC Tools untuk mengatasi masalah dalam proses produksi di organisasi [10]. Salah satu tujuan dari 7QC tools adalah untuk memperbaiki kinerja kualitas [10].

Diagram alir proses perbaikan kualitas adalah melalui proses review dari pihak manajemen menghasilkan data kondisi perusahaan dari yang tertinggi sampai terendah, misalnya jumlah produk reject terbesar sampai terkecil dengan menggunakan Diagram Pareto. Kemudian, memeriksa kondisi masa lalu dan terkini pada proses dengan menggunakan Lembar Kerja, Peta Kendali/Peta Kontrol, Histogram, dan Scatter Plot. Permasalahan yang dipilih selanjutnya dicari akar penyebabnya dengan menggunakan Diagram Fishbone. Pada akhirnya, perusahaan dapat menemukan solusinya, mengaplikasikan solusinya dan melakukan proses kontrol dari pengukuran kualitas tersebut hingga dapat dilakukan kembali proses review oleh pihak manajemen. Demikian seterusnya, dimana proses perbaikan akan dilakukan secara berkelanjutan atau disebut sebagai continuous improvement.

\section{METODE PENELITIAN}

Sesuai dengan desain penelitian, terdapat tahapan penelitian sebagai berikut: studi pendahuluan disertai dengan studi literatur, penentuan rumusan masalah dan tujuan penelitian, pengumpulan data (check sheet dan wawancara), pengolahan data pertama (histogram, diagram tebar, diagram pareto), pengumpulan tahap kedua yaitu pembuatan peta kendali, analisis dan pembahasan, kesimpulan dan saran. Tahapan penelitian dapat dilihat pada Gambar 1.

Penelitian dimulai dengan pembuatan studi pendahuluan diikuti dengan studi literatur. Studi literatur dilakukan untuk melihat perkembangan penelitian-penelitian terkini (state-of-the-art) dalam bidang yang berhubungan dengan penelitian ini. Dalam hal ini, pencarian literatur yang berhubungan dilakukan dengan menggunakan bantuan provider database google scholar dan proquest, dengan kata kunci: pengendalian kualitas, industri semen, seven tools.

Setelah merumuskan masalah dan memperoleh state-of-the-art, proses dilanjutkan dengan mengobservasi kasus yang terjadi di perusahaan tersebut dan mengumpulkan data. Data yang diambil adalah data kualitatif (kata, kalimat) dari hasil wawancara dan kuantitatif dari pengisian check sheet data jumlah produksi 


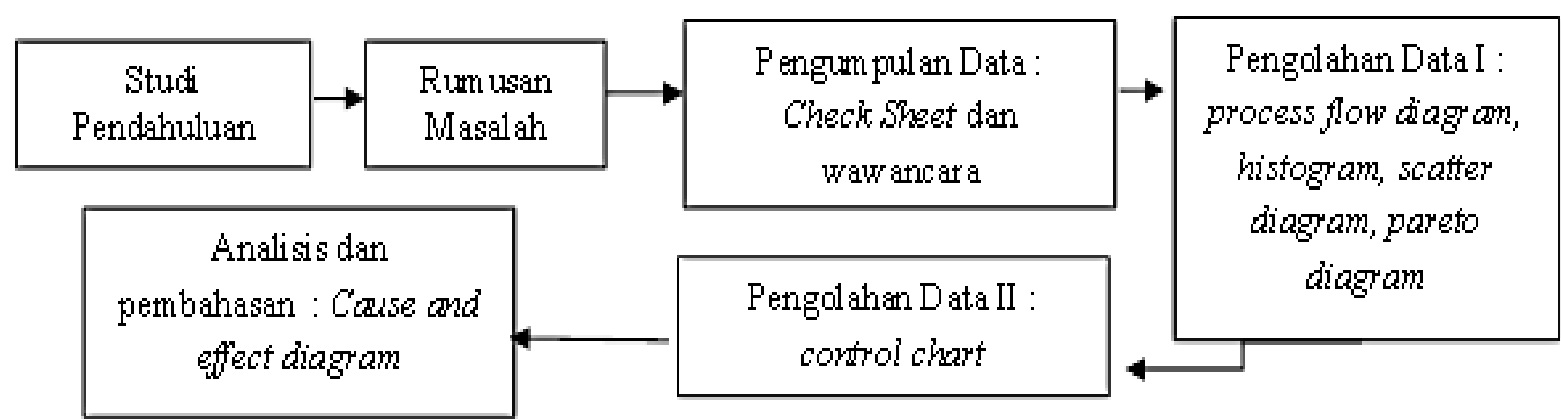

Gambar 1. Tahapan Penelitian

dan data jumlah reject dari bulan Januari sampai bulan Agustus 2016.

Proses dilanjutkan dengan pengolahan data dengan menggunakan histogram, diagram tebar, dan diagram pareto. Kemudian, dilanjutkan pengolahan tahap kedua, yaitu pembuatan peta kendali p. Alat analisis yang digunakan dalam tahap akhir ini adalah penggunaan diagram fishbone untuk mengetahui penyebab dari jenis kecacatan produk kantong semen yang menghasilkan reject terbesar. Kemudian, diberikan saransaran untuk mengatasi reject yang dominan tersebut.

\section{HASIL DAN PEMBAHASAN Proses Produksi Kantong Semen}

Pada proses produksi kantong semen Paper Bag Factory Section menggunakan mesin dan bahan baku yang digunakan untuk membuat kantong semen. Mesin dan kantong semen yang digunakan adalah:
A. Mesin

Berikut adalah data peralatan utama yang dimiliki PBF berdasarkan spesifikasi yang diberikan pabrik pembuatnya Newlong, Jepang. Peralatan utama yang dimiliki meliputi: (1) 1 unit Tubing Machine M645; (2) 1 unit Tubing Machine M12; (3) 1 unit Bottomer, Newlong Type 712 B, dan (4) 1 unit Bottomer, Newlong Type 712.

B. Bahan Baku

Bahan utama kertas kraft yang digunakan untuk Pasted adalah Kertas Kraft Extensibel yang diimpor.

Selain bahan utama yaitu kertas kraft, bahan lain pembentuk katong semen adalah Rope Polyamida, tinta warna merah dan biru, lem Procol 45, dan lem Emcol KP-45-KP

Pembuatan Pasted bag 2 ply dan 3 ply, 40 $\mathrm{kg}$ dan $50 \mathrm{~kg}$ melalui 2 tahapan proses yang menggunakan mesin Tubing dan mesin Bottomer. Gambar 2 merupakan bagan aliran proses produksi kantong semen pasted bag.

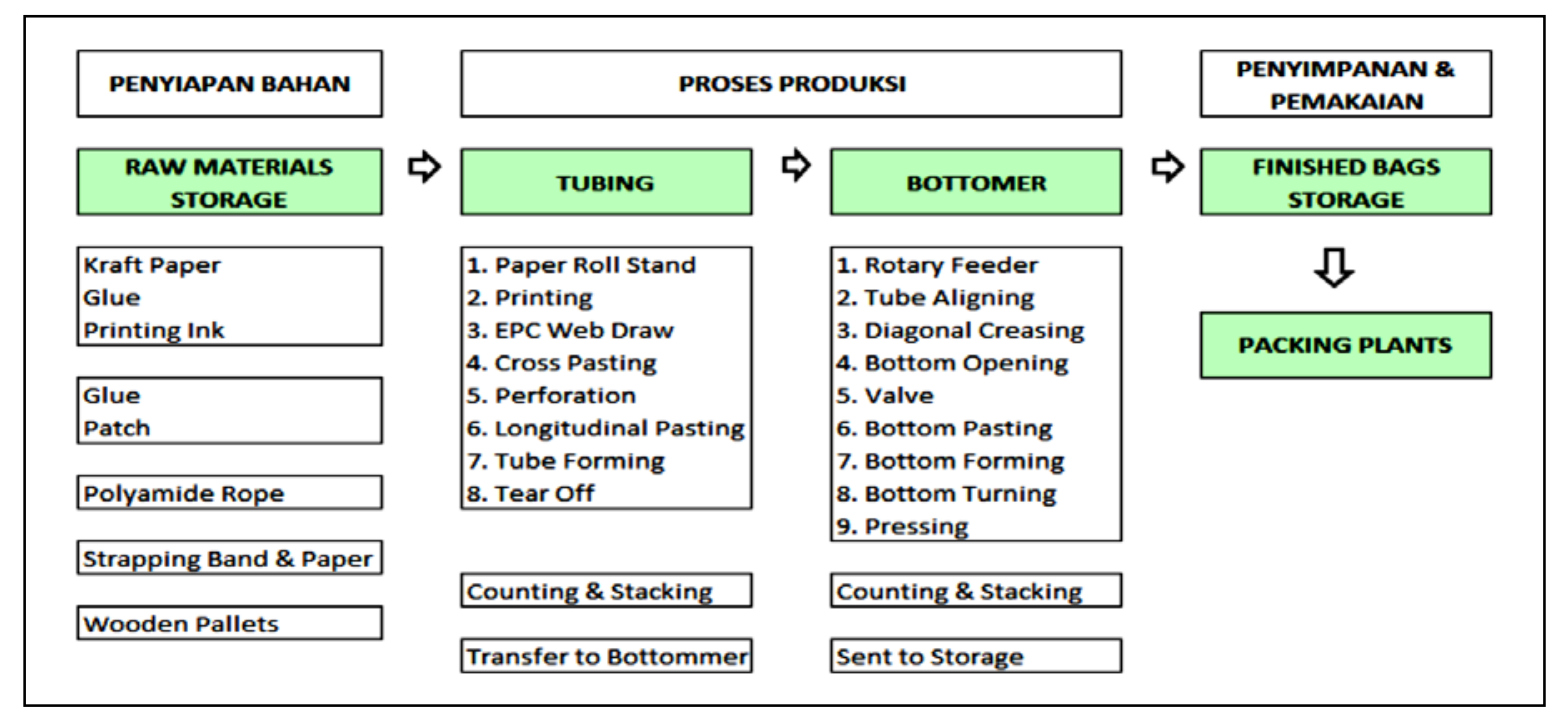

Gambar 2. Bagan Alir Proses Produksi Kantong Semen Pasted Bag. 


\section{Pengumpulan Data}

Data yang didapatkan dari PT XYZ plant Cirebon adalah data jumlah produksi dan jumlah produksi dan jumlah reject kantong semen pada bulan Januari sampai dengan bulan Agustus tahun 2016 (Tabel 1) dan tabel standar reject pada Tabel 2 .

Tabel 1. Jumlah Produksi dan Jumlah Reject Produk Kantong Semen

\begin{tabular}{ccccc}
\hline No & Bulan & $\begin{array}{c}\text { Jumlah } \\
\text { Produksi }\end{array}$ & $\begin{array}{c}\text { Jumlah } \\
\text { Kantung } \\
\text { Reject }\end{array}$ & $\begin{array}{c}\text { Persentasi } \\
\text { Produk } \\
\text { Reject (\%) }\end{array}$ \\
\hline 1 & Jan-16 & 4.584 .085 & 6.422 & $\mathbf{0 , 1 4 \%}$ \\
2 & Feb-16 & 4.576 .465 & 7.614 & $\mathbf{0 , 1 7 \%}$ \\
3 & Mar-16 & 4.824 .585 & 6.518 & $\mathbf{0 , 1 4 \%}$ \\
4 & Apr-16 & 3.737 .981 & 4.697 & $\mathbf{0 , 1 3 \%}$ \\
5 & Mei-16 & 3.346 .817 & 5.260 & $\mathbf{0 , 1 6 \%}$ \\
6 & Jun-16 & 3.848 .273 & 4.800 & $\mathbf{0 , 1 3 \%}$ \\
7 & Jul-16 & 4.024 .410 & 5.464 & $\mathbf{0 , 1 4 \%}$ \\
8 & Agu-16 & 6.604 .892 & 9.458 & $\mathbf{0 , 1 4 \%}$ \\
\hline \multicolumn{2}{c}{ Total } & $\mathbf{3 5 . 5 4 7 . 5 0 8}$ & $\mathbf{5 0 . 2 3 3}$ & $\mathbf{1 , 1 3 \%}$ \\
\hline Rata-rata & $\mathbf{4 . 4 4 3 . 4 3 9}$ & $\mathbf{6 . 2 7 9}$ & $\mathbf{0 , 1 4 \%}$ \\
\hline
\end{tabular}

Tabel 2. Standar Defect, Reject Dan Breakage Kantong Semen

\begin{tabular}{cccc}
\hline Material & $\begin{array}{c}\text { Pasted } \\
\text { Bag }\end{array}$ & $\begin{array}{c}\text { Pasted } \\
\text { Bag }\end{array}$ & $\begin{array}{c}\text { Pasted } \\
\text { Bag }\end{array}$ \\
\hline Parameter & Defect & Reject & Breakage \\
Target & $0,40 \%$ & $0,10 \%$ & $0,10 \%$ \\
Sampling & As Found & Daily & As Found \\
Frekuensi & & &
\end{tabular}

Paper Bag Factory Section memiliki suatu Flow Diagram Quality Plant dari proses produksi kantong semen pasted bag. Dari diagram ini dapat diketahui aliran proses produksi kantong semen dengan gambaran tindakan yang diperlukan pada setiap tahap proses produksi kantong semen bila terjadi kecacatan pada kantong semen. Diagram ini digunakan sebagai salah satu acuan bagaimana melakukan pengendalian kualitas pada proses produksi kantong semen (Gambar 3).

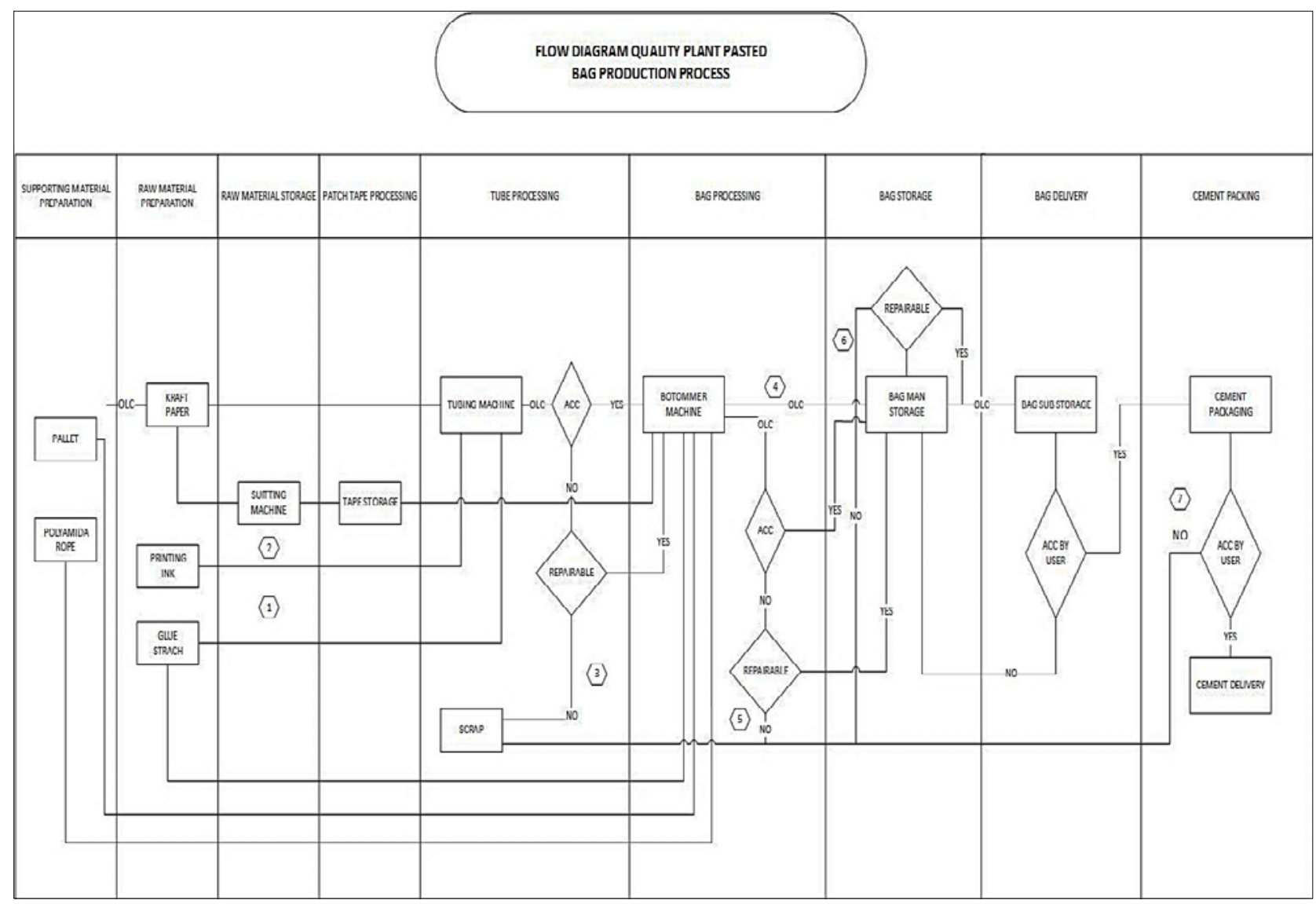

Gambar 3. Bagan Alir Proses Produksi Kantong Semen Pasted Bag 
Tabel 3. Jenis dan Jumlah Cacat Produk Kantong Semen pada Bulan Juni tahun 2016

\begin{tabular}{clc}
\hline No. & \multicolumn{1}{c}{ Jenis Cacat } & Jumlah Cacat \\
\hline 1. & Ujung Bottom Terkelupas Pada Pasted Bag & 10 \\
2. & Lebar Tube Menyimpang & 142 \\
3. & Cross Pasting Tipis Dan Kosong Pada Tube Pasted & 197 \\
4. & Jarak Overlap Dua Kertas Berurutan Menyimpang & 266 \\
5. & Longitudinal Pasting Tipis Dan Kosong Pada Tube Pasted & 302 \\
6. & Panjang Tube Menyimpang & 343 \\
7. & Cap Tidak Lengkap, Rusak Pada Tube Pasted & 660 \\
8. & Bottom Gagal Pada Pasted Bag & 2880 \\
\hline
\end{tabular}

\section{Pengolahan Data 1}

\section{Histogram}

Data yang digunakan pada pembuatan histogram (Gambar 4) adalah data jenis kecacatan yang terjadi pada bulan Juni tahun 2016 (Tabel 3).

Terlihat bahwa untuk nilai terbesar jenis kecacatan kantong semen tube pasted dan pasted bag terdapat pada jenis cacat poin 8, yaitu bottom gagal pada pasted bag.

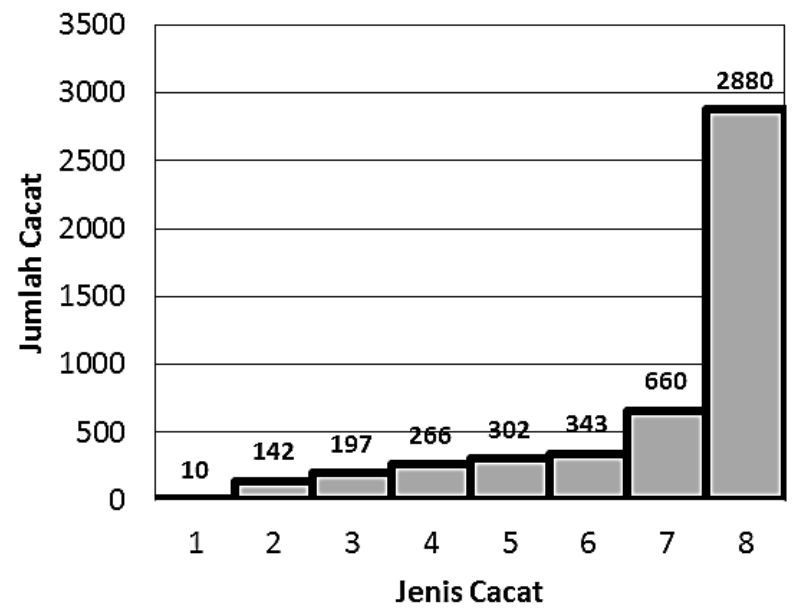

Gambar 4. Histogram Jenis Kecacatan Kantong Semen Tube Pasted dan Pasted Bag

\section{Diagram Tebar (Scatter Diagram)}

Pada gambar scatter diagram diagram tebar bahwa tidak terdapat hubungan antara persentase produk reject dengan jumlah produksinya. Setelah dilakukan proses perhitungan dengan menggunakan Microsoft Excel didapatkan nilai korelasinya (r) adalah sebesar 0,1 yang berarti bahwa tingkat korelasi sangat rendah atau bahkan mendekati tidak ada korelasi. Dalam hal ini mungkin dapat terjadi karena jumlah sampel yang diambil sedikit.

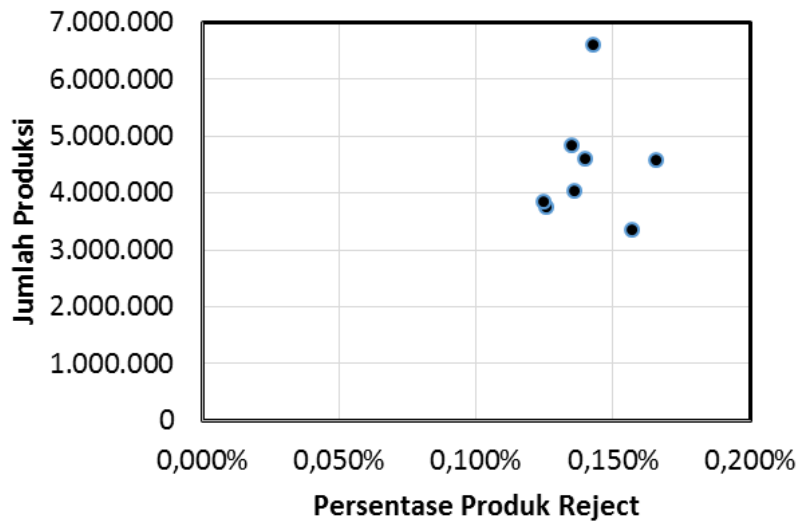

Gambar 5. Scatter Diagram Persentase Produk Kantong Semen Reject

\section{Diagram Pareto}

Pada analisis diagram pareto ini digunakan data kantong semen reject hanya periode bulan Juni 2016. Dari data yang digunakan diperoleh 8 jenis cacat yang menyebabkan reject pada produk kantong semen tube pasted dan pasted bag. Dibawah ini merupakan tabel dan gambar diagram pareto penyebab kantong semen reject.

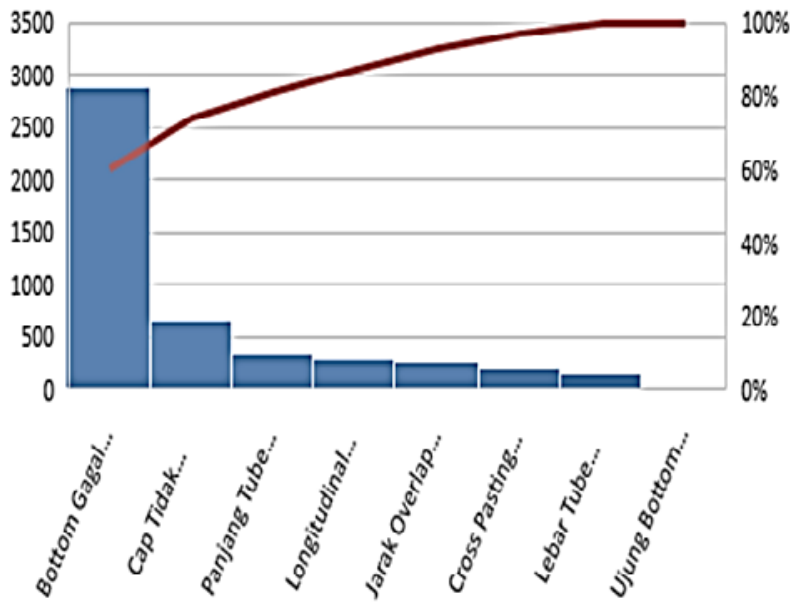

Gambar 6. Diagram Pareto Jenis Cacat Kantong Semen 
Tabel 4. Data Diagram Pareto

\begin{tabular}{clccc}
\hline NO. & Jenis Cacat & $\begin{array}{c}\text { Jumlah } \\
\text { Cacat }\end{array}$ & $\begin{array}{c}\text { Persentase } \\
\text { Cacat }\end{array}$ & $\begin{array}{c}\text { Kumulatif } \\
\text { Persentase } \\
\text { Cacat }\end{array}$ \\
\hline 1 & Bottom Gagal Pada Pasted Bag & 2880 & $60,00 \%$ & $60,00 \%$ \\
2 & Cap Tidak Lengkap, Rusak Pada Tube Pasted & 660 & $13,75 \%$ & $73,75 \%$ \\
3 & Panjang Tube Menyimpang & 343 & $7,15 \%$ & $80,90 \%$ \\
4 & Longitudinal Pasting Tipis Dan Kosong Pada Tube Pasted & 302 & $6,29 \%$ & $87,19 \%$ \\
5 & Jarak Overlap Dua Kertas Berurutan Menyimpang & 266 & $5,54 \%$ & $92,73 \%$ \\
6 & Cross Pasting Tipis Dan Kosong Pada Tube Pasted & 197 & $4,10 \%$ & $96,83 \%$ \\
7 & Lebar Tube Menyimpang & 142 & $2,96 \%$ & $99,79 \%$ \\
8 & Ujung Bottom Terkelupas Pada Pasted Bag & 10 & $0,21 \%$ & $\mathbf{1 0 0 , 0 0 \%}$ \\
\hline & $\quad$ TOTAL & $\mathbf{4 8 0 0}$ & $\mathbf{1 0 0 \%}$ & \\
\hline
\end{tabular}

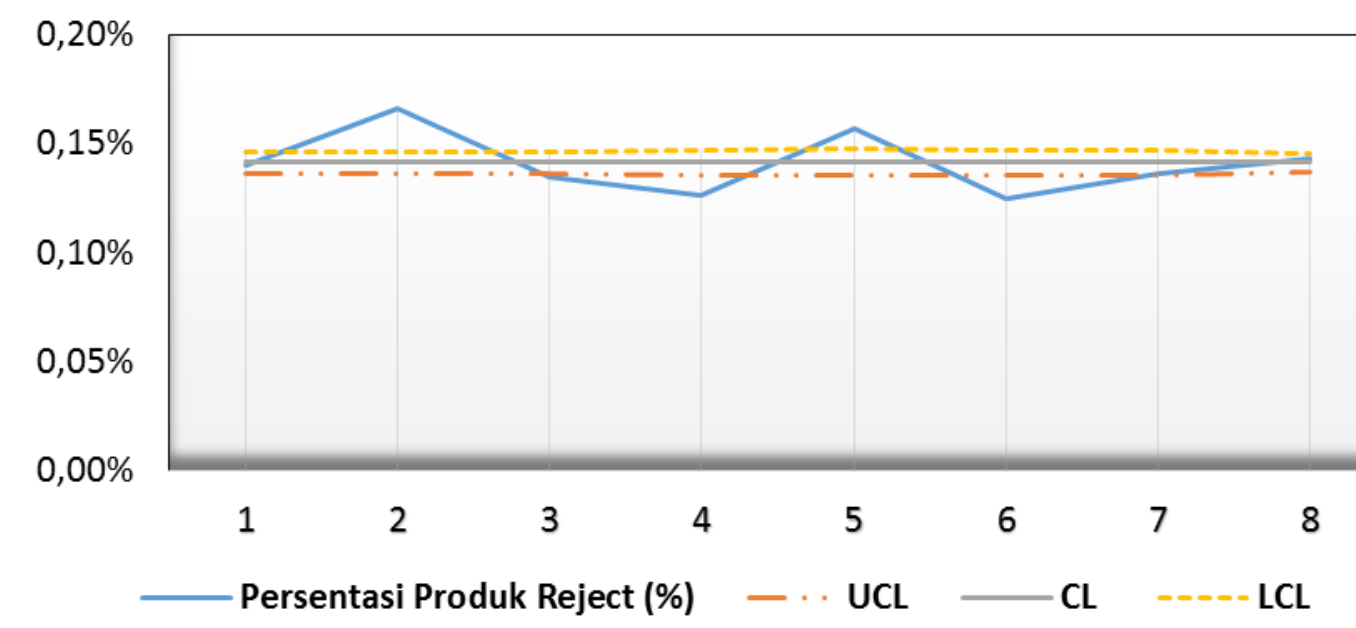

Gambar 7. Peta Kendali P

\section{Pengolahan Data II}

Pengolahan kedua ini dilakukan untuk mengetahui apakah data reject masih berada di dalam batas kendali atau tidak dengan menggunakan alat analisis peta kendali p. Pada pembuatan peta kendali p ini memiliki ukuran sampel yang beragam. Untuk menghitung proporsi cacat dari data reject keseluruhan adalah sebagai berikut.

$\bar{p}=\frac{\sum \text { jumlah produk cacat dan reject }}{\sum n_{i}}$

$\bar{p}=\frac{50.233}{35.547 .508}$

$$
\bar{p}=\mathbf{0 , 0 0 1 4 1}
$$

Nilai proporsi p juga digunakan sebagai nilai Center Line (CL) atau nilai tengah dari peta kontrol p. Selanjutnya penentuan deviasi standarnya, yaitu dengan rumus:
$S=\sqrt{\frac{\bar{p}(1-\bar{p})}{n_{i}}}$

Oleh karena nilai $\mathrm{n}$ bervariasi sehingga nilai standar deviasi juga bervariasi sesuai dengan nilai $\mathrm{n}_{\mathrm{i}}$.

Terlihat pada Gambar 7 bahwa data yang berada di luar batas kendali cukup banyak. Dari 8 data yang ada terdapat 5 data yang keluar batas kendali. Ini menunjukkan bahwa ada sebab-sebab tertentu yang membuat banyak data berada di luar batas kendali yang kemudian dicari penyebabnya dengan menggunakan diagram fishbone.

\section{Analisis dan Pembahasan}

Berdasarkan analisis diagram pareto diperoleh hasil tertinggi penyebab reject kantong semen adalah karena bottom gagal pada pasted bag maka dibuatlah diagram fishbone (gambar 8). Bottom gagal disebabkan oleh faktor man (kurang teliti, tidak ada 


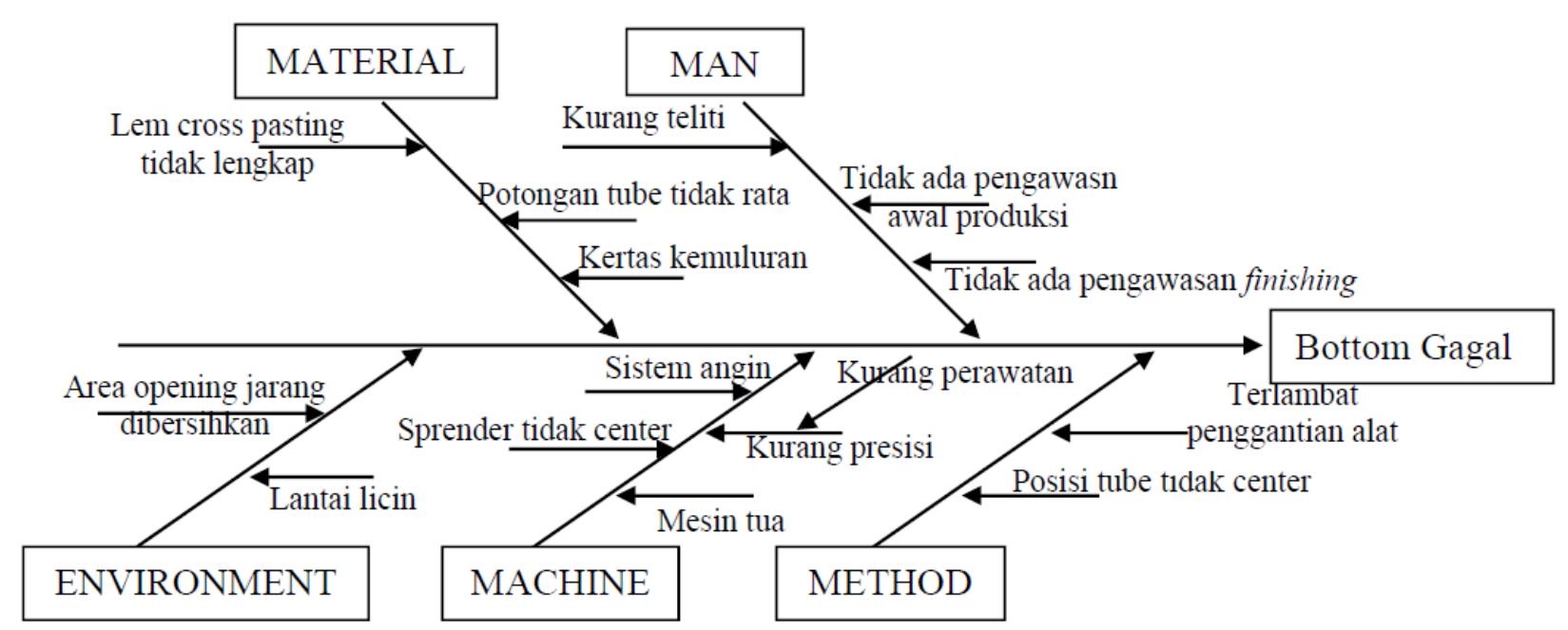

Gambar 8. Diagram Fish Bone untuk Cacat Bottom Gagal pada Kantong Semen Pasted Bag

pengawasan produksi awal dan finishing), faktor material (kertas kemuluran, potongan tube tidak merata, lem cross posting tidak lengkap), faktor metode (posisi tube tidak center dengan tubber secker, terlambat penggantian alat), faktor machine (mesin tua, sprander tidak center, kurang presisi karena kurang perawatan), dan faktor environment (lantai licin, area opening jarang dibersihkan).

\section{KESIMPULAN DAN SARAN}

Penggunaan seven tools dalam pengendalian kualitas di PT XYZ mampu memperlihatkan jumlah cacat yang terjadi (histogram), hubungan yang rendah sekali atau tidak ada korelasi antara jumlah produksi dengan jumlah cacat (diagram tebar), jenis cacat dominan yaitu bottom gagal dengan persentase $60 \%$ (diagram pareto), 5 data berada di luar batas kendali pada peta kendali $\mathrm{P}$, dan faktorfaktor penyebab dari cacat dominan dapat diketahui dengan menggunakan diagram fishbone. Saran untuk perbaikan adalah dengan melakukan maintenance secara rutin, pengecekan dan pembersihan tempat lem pada mesin, pemeliharaan lingkungan kerja, dan training kepada pegawai produksi agar dapat melakukan proses produksi disertai dengan inspeksi sesuai dengan standar operasional prosedurnya. Diharapkan agar perusahaan menggunakan seven quality control tools pada pengendalian kualitasnya agar kualitas dapat terkendali dan dapat mengetahui faktor-faktor penyebab terjadinya cacat serta dapat memperbaikinya.

\section{DAFTAR PUSTAKA}

[1]. Irmansyah, A. 2016. Kebutuhan Semen Meningkat Akibat Program Infrastruktur Jokowi. Diakses pada tanggal 10 Desember 2016 di http://kbr.id/08 2016/kebutuhan_semen_meningkat_akiba t_program_infrastruktur_jokowi/83814.ht $\mathrm{ml}$

[2]. Cahyani, F.I., Retnaningsih, S.M.. 2015. Analisis Pengendalian Kualitas Proses Pengantongan Semen di PT Semen Indonesia (Persero) Tbk dengan Pendekatan Six Sigma. Jurnal Sains dan Seni ITS Vol.4, No.2 : 2337-3520

[3]. Parwati, C.I. dan Sakti, R.M. 2012. Pengendalian Kualitas Produk Cacat dengan Pendekatan Kaizen dan Analisis Masalah dengan Seven Tools. Prosiding Seminar Nasional Aplikasi Sains \& Teknologi (SNAST) Periode III ISSN: 1979-911X Yogyakarta

[4]. Anis, M., Widyaningrum, R. 2014. Penggunaan Metode New Seven Tools untuk Pengendalian Kualitas Produk. Prosiding Seminar Nasional Teknologi Kimia, Industri, dan Informasi (SNaTKII I) Universitas Setia Budi

[5]. Ivanto Muhammad, 2010. Pengendalian Kualitas Produksi Koran Menggunakan Seven Tools Pada PT Akcaya Pariwara Kabupaten Kubu Raya, Program Studi 
Teknik Industri, Jurusan Teknik Elektro, Universitas Tanjungpura.

[6]. Jonathan, M.D. 2016. Analisis Pengendalian Kualitas untuk Mengendalikan Produk Cacat dengan Menggunakan Seven Tools (Studi pada PT. Mazebah Saroha-Jakarta). Skripsi fakultas Ekonomika dan Bisnis Universitas Diponegoro, Semarang.

[7]. Juran, J.M. 1998. Juran's quality handbook 5th edition. McGrawHill. New York.

[8]. Crosby, P.B. 1972. Quality is Free. Mc.Graw-Hill. New York.

[9]. Montgomery, C.D. 2009. Statistical Quality Control (6th ed). John Wiley \&Sons (Asia) Pte. Ltd. Asia.
[10]. Neyestani, B. 2017. Seven Basic Tools of Quality Control: An Appropriate Tools for Solving Quality Problems in the Organizations, MPRA (Munich Personal RePEc Archive) Paper No. 77681 online at https://mpra.ub.unimuenchen.de//77681/. 